\title{
What can ESL offer to the data collector? Describing, defining, designing and deploying an alternative ESL approach
}

\author{
Clare Fisher Williams*
}

Doctoral Candidate, SOAS, University of London

For the World Bank, the importance of the legal climate for attracting foreign investment is axiomatic and the legal and political aspects of an investment climate are measured in the World Bank's 'good governance' programme. However, the assumptions underlying this rely on quantitative research setting out correlation and highlighting a narrow range of voices. An ESL-inspired approach to empirical work can question what investors want from a host state legal system while also addressing criticisms of existing literature. As a case study, Sri Lanka is set out as a country actively engaged in attracting foreign investment through the creation of an ideal investment climate.

The discussion first describes the empirical by setting out the role of World Bank rationalities in shaping Sri Lanka's investment climate. It then defines the analytical, locating ESL in the social sciences and outlining the debates surrounding the central concept of embeddedness. It goes on to design an alternative approach by combining elements of three frames, both addressing existing criticisms and avoiding embeddedness. This is then deployed and the applications and implications for framing relations of foreign investors in Sri Lanka are set out.

\section{Describing the empirical - the role of a suitable investment climate}

$\mathrm{T}$ The scene is Colombo, Sri Lanka, October 2012, and the figures for 2013 are out. Having spent the past few years steadily climbing the World Bank's 'doing business' rankings, Sri Lanka has reached the lofty heights of 81 st place. ${ }^{1}$ Celebrations are in order, but so are future plans. '[T]he Government is targeting the 30th position by 2015', Central Bank governor Nivard Cabraal announces. ${ }^{2}$ This - he stated - could be achieved by improving aspects of the 10 'ease of doing business' indicators ranked by the World Bank. ${ }^{3}$

* With great thanks to Amanda Perry-Kessaris for ongoing support and guidance, and to Marie Selwood for her patience and understanding.

1 This was an increase of 15 places, up from 96th in 2012, making Sri Lanka the second most improved country in the world and the highest ranked for ease of doing business in South Asia. The ranking was later revised down to 89th place, although on current spreadsheets the 2013 ranking has been re-revised back up to 83rd position. Unfortunately, the 2014 figures have seen Sri Lanka slip two places in the rankings. See <www.doingbusiness.org/data/exploreeconomies/sri-lanka> last accessed 12 September 2014. The rerevisions are due to recalculations that reflect changes to the methodology and new information.

2 See <www.ft.lk/2012/10/27/lanka-aims-leapfrog-for-ease-of-business/> last accessed 12 September 2014.

3 According to the World Bank website, these 10 indicators are: starting a business; dealing with construction permits; getting electricity; registering property; getting credit; protecting investors; paying taxes; trading across borders; enforcing contracts; and resolving insolvency. See <www.doingbusiness.org/methodology> last accessed 12 September 2014. 
Sri Lanka's ultimate goal, reflected in the doing business rankings, was the creation of an investment climate that would attract foreign investment, itself seen as a catalyst for economic development. ${ }^{4}$ A strong belief in the role of the private sector in driving economic development - in particular, through foreign investment - underpins World Bank development programmes, along with a belief that higher levels of foreign investment will follow from the creation of an ideal investment climate. The legal and political aspects of the investment climate are contained in the World Bank's 'good governance' programme, which both advises and measures, publishing annual 'rankings'. 5 The Bank therefore counts within its field of competence all areas of statecraft likely to impact the developing state, including rule of law reforms deemed vital for good governance and sustainable economic development. ${ }^{6}$ Yet, while there is a great deal of research into relations between law and foreign investment, dominant approaches rely on quantitative regression analyses of (sometimes proxy) indicators. In other words, while there is a body of research establishing correlation between the investment climate and levels of investment, there is little that has focused (qualitatively) on causation. Moreover, the partiality of perspectives relied on in much existing research privileges economic (commercial) voices, often at the expense of other actors (both state and non-state) who can be impacted both by the effects of World Bank indicators and by the legal reforms that follow.

The quantification of legal systems by the Bank reflects the rise over the past half century of normative and analytical approaches that have seen the application of natural science methods to the social sciences, particularly in economics. The importance of law for the economic well-being of a country was explored by the law and development movement in the 1960s, however, law's full potential to be 'applied' in the pursuit of development was fully quantified in the law and economics movement. ${ }^{7}$ This also echoed the ascendancy of economics as an analytical, empirical and normative method of choice throughout the social sciences and, as 'economics imperialism'8 or 'market colonization'" came to dominate the social sciences, the privileging of some (economic) voices over alternative perspectives and critical analyses became inevitable.

In response to this, economic sociology of law (ESL) offers tools for exploring the relations of foreign investors with the law in a way that responds to the criticisms set out above. In particular, by placing empirical work in a sociological frame, the perceptions and motivations of investors can be explored, moving us beyond correlation to causation. The approach also lets us include a broad range of voices and interactions without privileging one set of interests over others, including interactions between - in the Sri Lankan example - foreign investors, local businesses and various other groups of actors throughout society. By looking at the full spectrum of interactions, we can begin to understand the importance

4 For the 2013 ranking, the World Bank recognized Sri Lanka's progress in computerising several processes relating to land registry, export regulations and compliance resulting in expedited processes (see $\mathrm{n} 2$ ). But, if Sri Lanka was to reach 30th position by 2015, there was much more to be done. The ease of setting up businesses, getting permits and accessing infrastructure had to be improved and there were calls for 'one stop shops' to be set up online.

5 For information on the six 'dimensions' of the governance programme and the latest data, see <info.worldbank.org/governance/wgi/index.aspx\#home> last accessed 12 September 2014.

6 See <http://go.worldbank.org/YAUOR8VO20> last accessed 12 September 2014. See also World Bank, World Development Report 2005: A Better Investment Climate for Everyone (OUP 2005) 1.

7 The extent of the leximetric approach is best exemplified by the seminal work of F Lopez, R La Porta, A Schleifer and R Vishny, 'Legal Determinants of External Finance' (1997) 52 Journal of Finance 1131.

8 See A Perry-Kessaris, 'Prepare your Indicators: Economics Imperialism on the Shores of Law and Development' (2011) 7(4) International Journal of Law in Context 401-21.

9 See M Chossudovsky, The Globalisation of Poverty (Zed Books 1999) 37. 
of the legal system to one group without sidelining the impact on others. This may in turn highlight normative areas of conflict resulting from foreign investment, while at the same time addressing the balance of economics as a dominant approach.

To empirically explore the importance of the host state legal system for foreign investors, three main questions are relevant. Firstly, to what extent are investors sensitive to the host state legal system? Secondly, does this sensitivity vary according to the nationality of the investor and, thirdly, does it vary according to the sector in which they are engaged? Through interviews with foreign investors in Sri Lanka, answers to these questions will expand existing knowledge about how foreign investors interact with the law. For example, do they extensively research the shape of the host state legal system prior to investing? If so, were they encouraged or discouraged by the results? Answers to these can then feed in to questions of what Sri Lanka can do, proactively, to attract foreign investment. Can it, through targeted legal reforms, create a climate that attracts investment in particular sectors and/or from specific parts of the globe? Moreover, how can Sri Lanka make sure that any legal regime designed to attract foreign investment also protects and supports local and international networks that operate alongside the legal system while at the same time not disadvantaging both domestic business operators and other local voices? By using ESL to frame the empirical research, the answers can highlight a range of interests and voices, while also valuing existing social networks and structures within Sri Lanka, ultimately leading to more constructive and inclusive proposals.

Section 2 sets out to define ESL and locate it in the social sciences. ESL lacks a single clear methodology, and there has been significant disagreement over the usefulness of the central concept of embeddedness. To this end, section 3 designs and deploys an alternative, combined approach that uses elements of three socio-legal or sociological frames. The first takes Cotterrell's communal networks approach and discusses how this can provide an alternative to embeddedness. It also allows the researcher to highlight certain degrees and levels of interaction among specific actors without losing sight of the complex social ties and diverse interests that they have. Consequently, a communal networks approach challenges the normative and analytical privileging of economic voices that has shaped much of the existing research. The second approach again takes communal networks as a starting point, but expands it across Frerichs' four levels of sociological analysis, seeing law and economy as normatively expressed and constructed in regimes and cognitively expressed and constructed in rationalities. The constructivist impact of regimes, underpinned and produced by rationalities, on the actor and her interactions introduces elements of the cognitive turn, which is brought out further in the third approach. This uses feedback loops set out in Gidden's structuration theory to build on the combined approach of communal networks and four analytical levels of the second approach. The discussion shows that a focus on feedback loops between the actor and her environment, and between the researcher and the field of investigation, are important for a fuller understanding both of the wider impact of foreign investment and law reform and of the impact of carrying out the research. The fourth section looks at the applications and implications of deploying a combined approach, and sets out how and why it is necessary to address the complex questions and issues raised by research into foreign investment in Sri Lanka. It shows how, by taking a communal networks approach and introducing a cognitive analysis, the frame both moves beyond the embeddedness debate and expands our understanding of investors and the law. By doing this, it addresses criticisms of current research (both the partiality of perspectives and reliance on correlation), while also challenging the World Bank belief in the one-size-fits-all investment climate. 


\section{Defining the analytical - what is an economic sociology of law?}

Despite being introduced in myriad works, ESL is not given to neat, succinct definitions with a clear methodology. Nevertheless, there is a general consensus that it represents 'shared understandings of how and why one might use sociologically-inspired approaches (analytical, empirical and normative) to investigate relationships between legal and economic phenomena'. ${ }^{10}$ Perhaps because of this - the fact that ESL is more of a state of mind than a fixed methodology - there is a great deal of diversity in approaches and foci. More concretely perhaps, Frerichs notes that ' $\mathrm{t}$ ] he proper subject of studies in the economic sociology of law ... consists in the economic constitutions that make up market society'. ${ }^{11}$ It therefore 'mediates between the perspectives of legal sociology, on the one hand, and economic sociology, on the other'. ${ }^{12}$ At the same time, though, it is important to bear in mind the centrality of a particularly sociological starting point, or lens, through which the interrelations between these spheres can be studied. Having established this, though, we then have an extensive array of sociological lenses or tools to choose from, ranging from the socio-legal communal networks lens (Cotterrell, Perry-Kessaris) ${ }^{13}$ to relational work (Zelizer, Block), ${ }^{14}$ via sociological levels of analysis based on the embeddedness paradigm (Frerichs, Perry-Kessaris) ${ }^{15}$ to the more constructivist theories of the 'third generation' of sociologists (Luhmann, Habermas, Bourdieu, Foucault). ${ }^{16}$ Each of these offers a different point of departure and focus. Some deal directly with the dualisms that have developed in modern sociology (agency/structure, ontology/epistemology, realism/constructivism, macro/micro, embeddedness/relatedness and so on), while others instead have a more particular locus of interest. ${ }^{17}$ Of central concern across the ESL spectrum, however, is the notion of embeddedness - deploying it, redefining it or avoiding it.

Despite Polanyi's hints at the embeddedness of the economy in society, the notion remained shelved until its revival by Granovetter in 1985 with his concept of social networks and the embeddedness of markets in 'law, politics, culture and social arrangements'. ${ }^{18}$ The concept became central to economic sociology, and was carried over into its offspring, ESL. ${ }^{19}$ Since then, it has more recently been termed the 'core concept' or the 'lowest common denominator' of economic sociology and has become the ubiquitous

10 D Ashiagbor, P Kotiswaran and A Perry-Kessaris, Towards an Economic Sociology of Law (Wiley-Blackwell 2013) 2. Swedberg notes that the focus of ESL should be on the role that 'law and regulations play in the economic sphere'. See R Swedberg, 'The Case for an Economic Sociology of Law' (2003) 32 Theory and Society 1, 2.

11 S Frerichs, 'The Legal Constitution of Market Society: Probing the Economic Sociology of Law' (2009) 10 Economic Sociology, The European Electronic Newsletter 3 July 2009, 24.

12 S Frerichs, 'Studying Law, Economy and Society: A Short History of Socio-Legal Thinking' (2012) Helsinki Legal Studies Research Paper No 19, 5.

13 R Cotterrell, “Rethinking Embeddedness”: Law, Economy, Community' and A Perry-Kessaris, 'Anemos-ity, Apatheia, Enthousiasmos: An Economic Sociology of Law and Wind Farm Development in Cyprus' both in Ashiagbor et al (n. 10).

14 V Zelizer, 'How I Became a Relational Economic Sociologist and What Does That Mean?' (2011) Centre for the Study of Social Organization, Working Paper No 5, available at <www.princeton.edu/csso/workingpapers/WP5.pdf> accessed 21 April 2014; and F Block, 'Relational Work and the Law: Recapturing the Legal Realist Critique of Market Fundamentalism' in Ashiagbor et al (n 10).

15 Frerichs (n 11); Frerichs (n 12); Perry-Kessaris (n 13.).

16 For more on the three generations of sociological thinking, see S Frerichs (n 12).

17 For a more detailed account of the use of sociological paradigms in legal and economic analysis and the history of socio-legal thought, see ibid.

18 M Granovetter, 'Economic Action and Social Structure: The Problem of Embeddedness' (1985) 91(3) American Journal of Sociology 481-510.

19 See R Cotterrell (n 13); and Block (n 14). 
central concept of ESL. ${ }^{20}$ Despite its entrenchment in ESL though, there have been questions over its value. ${ }^{21}$ As a 'relatively blunt instrument for analysing different types of market structures and arrangements' the concept lacks subtlety, ${ }^{22}$ while a more fundamental flaw in the concept has been described. ${ }^{23}$ Granovetter's original use of the term insisted 'on the separate nature of economy and society', 24 thereby differentiating the economy from society. The resulting unavailability of the economy to sociological analysis left economic sociology confined to analysing the social contexts of the market, rather than the market itself. This arguably left embeddedness-based-ESL unable to realise its goal of integrating scholarship and empirical analysis of law, the economy and society. ${ }^{25}$

Accordingly, opinions were split over whether the future of embeddedness lay in an effort 'to strengthen it and try to improve it', ${ }^{26}$ or whether it should be dispensed with in favour of an alternative. ${ }^{27}$ 'Thin' and 'thick' notions of embeddedness where all markets, even the most impersonal, are seen as 'deeply social, and deeply political and cultural' offer a Polanyian reading. ${ }^{28}$ Alternatively, embeddedness can be narrowed to describe the cognitive or normative expression of the economy in society on different levels of sociological analysis. ${ }^{29}$ The question has also been raised whether the so-called 'cognitive turn' of many third-generation sociological theories offers us a way to move beyond embeddedness; ${ }^{30}$ whether in fact an alternative exists that focuses on the reflexive internalization of the environment by the actor and the reproduction of norms and institutions through repeated interactions. This possibility is explored in the combined approach to the empirical work set out here where all talk of 'embeddedness' is avoided. Instead, the focus is on the expression and construction of aspects of interactions that reproduce specific interests.

\section{Designing and deploying the analytical - building an alternative approach}

\subsection{FRAMING INTERACTION: COMMUNAL NETWORKS}

Much like ESL itself, a law and community approach takes community not as a social object, but as a way of thinking about social relations. ${ }^{31}$ A communal networks lens is useful in the study of foreign investors in Sri Lanka because it offers us a framework for analysing certain interactions and groups within society. It highlights the possibility that at any one time actors are engaged in multiple spheres of interaction on different levels of stability and trust

20 S Frerichs (n 11) 20. This has also been echoed in G Krippner et al, 'Polanyi Symposium: A Conversation on Embeddedness' (2004) 2 Socio-economic Review 109-35, 110.

21 For a comprehensive review of Polanyian embeddedness, see A Ebner, 'Transnational Markets and the Polanyi Problem', in C Joerges and J Falke (eds), Karl Polanyi, Globalisation and the Potential of Law in Transnational Markets (Hart 2011) 19-40.

22 Block (n 14) 39.

23 Cotterrell (n 13).

24 Krippner et al (n 20) 112-13.

25 Cotterrell (n 13) 51.

26 Block (n 14) 117. Krippner has questioned whether we could dispense with concept, given its ubiquity and pervasiveness. See Krippner et al (n 20) 125.

27 Proposing this view, Cotterrell suggests the communal networks lens as an alternative that can illuminate 'the social character of both law and economic relations'. See Cotterrell (n 13).

28 Block (n 14) 128.

29 Frerichs (n 11) 23. This approach also echoes Block's assertions on the moral embeddedness of the markets: Block (n 14) 118.

30 Frerichs (n 12).

31 R B M Cotterrell, Law's Community: Legal Theory in Sociological Perspective (Clarendon 1996) 55. 
and each with varying combinations of (Weberian) ideal types. Some interactions may be fleeting while others are more permanent, however, interactions with a degree of stability and which are underpinned by mutual interpersonal trust are seen as networks of community accordingly. By relying on ideal types to characterize aspects of an interaction, the communal networks lens answers one of the main criticisms of embeddedness - that by seeing the market as embedded in society we entrench their separateness and 'black box' the market. ${ }^{32}$ Instead, by taking economic relations as an aspect of social interaction, both the economic and the legal are seen as different aspects of the same (social) entity, rendering both available for sociological analysis on the same terms as cultural and political factors.

By using this approach we can simultaneously consider not just the instrumental (in particular the commercial) expectations of foreign investors, but broader sets of interests to understand the regulatory requirements and potential impact of legal reforms. Foreign investors in Sri Lanka may be looking for more than simply profit. They may have traditional (share a common language), affective (family ties to the country), or belief-based (Buddhist or Muslim, for example) ties to Sri Lanka. And at any one time actors (investors) are engaged in multiple types of relationships with a range of other actors, varying in permanence and stability but each displaying a combination of ideal types. In short, a community approach encourages us to see investors as more than the impartial, utilitymaximizing, one-dimensional actors that traditional economic models rely on.

The lens also encourages us to consider a broader range of actors. Legal reform in pursuit of a suitable investment climate will likely impact on domestic businesses and other actors. In addition to investors themselves (Chinese and American, operating in both primary and tertiary industries), other actors that may be affected include Sri Lankan state and government actors (law-makers and enforcers, regulatory bodies, trade delegations and diplomatic undertakings), local businesses (owners, employers, employees, shareholders, trading partners), ${ }^{33}$ banks and finance institutions (local, foreign and international banks, trading houses), insurers, and last but not least, local communities (community leaders, interested parties, civil society groups and actors). ${ }^{34}$ Local communities are likely to have local trade-based interactions or be employers or employees (instrumental). But they are also likely to have a deep empathetic attachment to their locale (affective) and may (or may not) believe that economic development is best carried on by local enterprises (belief), leading them to embrace (or resist) increasing development.

While the World Bank may prioritise the instrumental (commercial) needs of investors, the role of law in maintaining and enhancing trusting relations of community throughout society while supporting more fleeting interactions means that the wider impact of changes is important. The impacts on social cohesion and trust across society can and should be given equal weight when looking at legal reforms in pursuit of economic development. The law and community lens sees networks extending across societies, nations, and even internationally, and recognizes the shifting patterns and nature of these. However, it might be helpful in the Sri Lankan scenario to examine the wider effects of interaction patterns across social groups throughout space and time. How and where is the structure challenged and what is the importance of the reactions and inter-reactions of other actors?

32 Cotterrell (n 13) 52.

33 These are businesses and businessmen and women local to the sites of major foreign investment. This includes the major cities across Sri Lanka, but also the Special Economic Zones and Investment Parks that are dotted around the country.

34 Sri Lanka has a thriving civil society 'industry'. There are an estimated 20,000 to 50,000 civil society organisations operating within the country. See Asian Development Bank, Civil Society Briefs, available at <www.adb.org/sites/default/files/pub/2013/csb-sri-lanka.pdf> last accessed 16 April 2014. 
Furthermore, the communal networks approach on its own does not delve into the subjective understanding of actors - how do investors from one background respond to a different legal system operating in a different cultural and social setting? How does their interpretation of these inform their actions, and how are these actions constrained or enabled by the structures and institutions put in place to benefit them? These questions can be addressed by expanding the communal networks lens.

\subsection{FRAMING INTERACTION COGNITIVELY: COMMUNAL NETWORKS EXPANDED}

The communal networks lens highlights particular interactions and reveals the complex regulatory requirements of certain groups brought out by combinations of ideal-type interactions. But 'investors' are a diverse group with different backgrounds, cultures, attitudes, interests and motivations and, to understand the way in which these cognitive taxonomies impact on their interactions, we can expand the communal networks approach across the four levels (micro, meso, macro, meta) of sociological analysis. ${ }^{35}$ Regimes and the rationalities underpinning how those regimes are interpreted and (re-)constructed offer a way of conceptualising the cognitive and normative aspects of various ideal-type interactions. They also take into account the divergence in approach, perception, understanding and reproduction of norms and practices by diverse groups of individuals.

At the micro-analytical level the focus is on actions and interactions, such as between a foreign investor and another investor or a representative of the Sri Lanka Board of Investment. Further down the line, this will also include interactions between investors and employees (members of the local community or between friends), or, if things go wrong, with lawyers or judges. Reflecting the continued use of the communal networks lens, interactions will include all ideal types, spanning the fleeting to the stable, trusting relations of community. ${ }^{36}$ For an investor, a fleeting business interaction with another (unknown) actor is likely to privilege economic factors over the non-economic (the likelihood of a profit over other considerations of family, culture, or local development). However, stable and sustained interactions, or prior knowledge of the other actor, may modify this to include other aspects.

The meso-analytical level focuses on relations; a series of interactions that extend throughout space and time and are increasingly patterned. ${ }^{37}$ These eventually extend and coalesce into regimes (macro-analytical level) that comprise 'complex institutional constellations that connect - and thus integrate - different spheres of action'. ${ }^{38}$ Thus, at the meso-level we can include patterns of interactions between, say, an investor and the Board of Investment, ${ }^{39}$ while at the macro level we can include the law and the economy as

35 While this approach is based explicitly on an - albeit altered - embeddedness paradigm, for the purposes of clarity, and because the communal networks lens offers a way of avoiding the term altogether, I instead refer to the mutual expression and construction of rationalities and regimes through repeated interactions in a way that reflects the centrality of the cognitive dimension.

36 For a visual illustration of the complex myriad interactions, see Perry-Kessaris (n 13) 70. A simplified version of this can be found in A Perry-Kessaris, 'The Case for a Visualized Economic Sociology of Legal Development' (2014) Current Legal Problems, 14.

37 The idea of extension across space and time takes on more significance in the context of structuration (below), but is a useful notion here for differentiating the fleeting interactions from those which are more patterned.

38 Frerichs (n 11) 20.

39 The Sri Lankan Board of Investment website now lists names and contact details of individuals at the Board who will guide the prospective investor through the entire investment process, offering guidance, legal advice, checklists and in-country contacts. This is intended to be a lasting relationship, extending beyond the initial investment to support the foreign investor. See <www.investsrilanka.com/investor_relation_center> last accessed 21 August 2014. 
examples of regimes. The meta-analytical level locates the rationalities underlying and informing any given regime, or the 'abstract, epistemic categories located in the "deep" structure/culture of society'. 40 The economy, as a regime, is played out in society through repeated interactions that coalesce into accepted institutions (ways of doing things) and rationalities (ways of thinking about things) that are commonly shared across groups, or networks of community. At the meta level, economies - expressed through and shaped by economics - are cognitive aspects of social interaction in the sense that they are 'moral, scientific or cultural constructions'. ${ }^{41}$ Similarly, at the macro level, a regime such as the economy is a normative aspect of repeated interactions. To put it differently, economies are normatively expressed as regimes through repeated interactions. They are given institutional form and to a greater or lesser degree shape the actions of actors depending on their rationalities. So, primarily instrumental relations are cognitively expressed and constructed on the meta level through economics and normatively expressed and constructed on the macro level in the form of economy. We can make the same statements about law as a regime. Moreover, the cognitive and normative aspects that are expressed and constructed through interactions also have a constructivist impact on the actions of actors who reproduce (or challenge) the regimes and rationalities in their actions. ${ }^{42}$

Given that rationalities are central to the recognition, interpretation and reproduction of regimes and that both may change over time, the epistemic categories of investors are crucial to understanding how a particular legal regime will be apprehended, interpreted and enacted by investors. While rationalities will differ slightly from one individual to the next, it is reasonable to assume shared notions of 'doing business' and 'using the law' among groups of investors from similar cultural backgrounds. But it might also be reasonable to suppose differences in broad approaches between groups of different backgrounds. While one investor (American) may expect the law to play a pivotal role in the structuring of relations with other parties and the resolution of disputes, another (perhaps Chinese) may prefer to take a different approach that avoids the formal legal system altogether or makes different demands of it. This immediately challenges the one-size-fits-all ideal investment climate proposed by the World Bank. Frerichs notes that regimes and rationalities shift over time and notions of 'best practice' and 'how to do business' among groups of investors within one jurisdiction (operating under one regime) may assimilate. However, given the cognitive and interpretative centrality of rationalities to the construction and expression of regimes, it is suggested that both legal and economic regimes and rationalities among investors and other (domestic) stakeholders need to be aligned as closely as possible for interactions to become stable, sustained and underpinned by mutual interpersonal trust.

By using the four analytical levels to incorporate a version of the so-called 'cognitive turn' into the communal networks lens, we can explore the relevance of epistemic categories on investors' expectations, requirements and actions. However, this approach does not express the full potential of the feedback loops in social interaction, or look at the extent to which the actor's perception of her environment contributes to creating her reality and her actions within that reality. Further, while regimes and rationalities change over time, we have not explored how this happens. The next section adds further feedback loops to the combined approach set out here and explores the implications of these for the research.

40 Frerichs (n 11) 20.

41 Ibid.

42 The full extent of this feedback loop is expanded in the following section. 


\subsection{FRAMING INTERACTION COGNITIVELY ACROSS SPACE AND TIME: STRUCTURATION}

The combined approach set out goes a long way to providing a suitable ESL-inspired lens through which to examine the interaction of foreign investors in Sri Lanka with the legal system and assess the relative importance of the latter. But it can be enhanced with the dual feedback loops from structuration theory that occur, firstly, between the actor and her environment and, secondly, between the researcher and the field of enquiry. Through this first feedback loop, structuration also highlights the importance of the spreading-out across space and time of social practices - how practices spread throughout society locally, nationally and internationally and how these are affirmed, challenged, altered, coalesce or collapse. This aspect is crucial to the way in which interactions eventually form institutions and encourages us to take a broader perspective on the implications of practices and interactions across society than is captured in the previous approaches.

Institutions, or regimes, are reflexively internalised and reproduced by the actor in her interactions, which are in turn perceived, understood, internalised and reproduced (or challenged) by other actors, and so on throughout a group and beyond. Thus, there is a significant feedback loop between the actor and the structure that both informs and results from her actions; she is a product of her (social) environment as she perceives and understands it and as she reproduces it. This foregrounds how some regimes are prioritised by some groups of investors and ignored by others. Certain (legal) aspects of interactions may simply not feature on the radar of some investors and as such are significantly less relevant to them, while for others these might be vital factors determining viability of investment. ${ }^{43}$ Thus, for some the formal legal system may not comprise a great deal of their social reality (if at all) and will not be constructed by them in interactions. This is then perceived and reproduced by other actors within the group and so the practices spread like memes across space and time. Conversely, an investor in a knowledge-based industry is more likely to perceive and reproduce the legal practices and norms that are important to them, again being replicated by others they interact with. The point to note here, and why this expands the previous discussion of rationalities, is that the feedback loops between regimes and rationalities as expressed and constructed by the actor through interactions, depend on the perception of the actor and her total knowledge deriving from her background and the environment she is operating in. This again emphasises the importance of the investor's background and field of operation in understanding the formation of her rationalities and how these construct her reality and that of those around her.

These feedback loops also highlight the extension of such approaches throughout groups of investors, and even of wider collectivities in general. Of particular interest are the so-called 'transformation points', or the points at which the existing structures, regimes and rationalities are challenged. For example, if regimes of best practice among the business community dictate that $\mathrm{X}$ is followed in a specific situation and an investor instead follows $\mathrm{Y}$, what is the response to this? Is disapproval expressed, thereby affirming $\mathrm{X}$, or do other businesses, noting perhaps an advantage of $\mathrm{Y}$, also choose to follow this practice in future? How does this challenge or acceptance feed back to alter, or reaffirm, existing regimes? Much of this may occur at the sub-discursive level where actors do not verbalise the reasons for their actions but understand on a deeper level the demands and constraints of coexisting as a social actor.

43 Natural resource extraction is one industry where the shape of the legal system (in particular, aspects of the rule of law) is significantly less important, especially in comparison to manufacturing or knowledge-based industries (from informal discussions with mining industry experts). 
The second feedback loop of direct relevance to empirical work is the so-called 'double hermeneutic'. ${ }^{44}$ This applies throughout the social sciences and refers to the potential for social science ideas to 'leak' into the real world. If taken up, these ideas can feed in to social practices, due to the feedback loop set out above, and can alter the way actors think and act. Thus, interviewing investors on their attitudes to the legal system may inadvertently cause a shift in attitudes among those investors, altering the reality that the research originally set out to understand. At the same time, there is the possibility that investors are aware that the World Bank (and in turn received wisdom) states that they should be sensitive to the legal system, in effect drawing their attention to this aspect of the host state and highlighting what was originally perhaps a minor concern. ${ }^{45}$ This is not necessarily a problem for the research, so long as feedback loops and actor reflexivity are kept firmly in mind for the purposes of understanding actor interests and motivations and how these construct and are constructed by regimes and rationalities.

\section{Deploying the analytical and normative: applications and implications of a combined approach}

The discussion so far has assessed what it means to use an ESL-inspired frame to look at the importance of the legal system for foreign investors in Sri Lanka. It has outlined some of the main problems with embeddedness and has set out an alternative approach that replaces the term. Instead, as both communal networks and structuration theory suggest, economic or legal interactions can be seen as aspects of the social, reproduced in repeated interactions. A communal networks lens, firstly, lets us identify, categorize and highlight those complex sets and patterns of interactions directly relevant to the research questions, while keeping in mind wider groups and relations throughout society that may be impacted. The community lens lets us identify, compare and contrast the regulatory needs of various groups of investors, but also of diverse groups throughout society who should not be disadvantaged by the creation of an investment climate designed to attract foreign investment.

Secondly, in challenging the World Bank assertion that there is a single investment climate that is ideal for all investors, we can identify and understand the rationalities of investors (how they think about law) and their regimes (how they 'do' law). This highlights not only what might be important to investors but how requirements and priorities change according to their sector and background, and even over time. Cognitive and normative expression and construction of rationalities and regimes by the actor can be explored and we can see how pre-existing frames of reference (cultural, political, economic, linguistic, etc.) can impact on the (re-)construction of institutions in diverse sets of interactions.

Thirdly, the importance of feedback loops to spread regimes and rationalities across broad areas of space and time are significant for understanding why some groups of investors might have similar approaches and needs to others and how these can alter. These feedback loops also enhance the constructivist role of rationalities in shaping both the actor and her interactions, while at the same time the potential of research on the social science environment to alter the reality of actors through further feedback loops is flagged.

44 A Giddens, The Constitution of Society (Polity Press 1984), 284, 374. Set out here is a much reduced and simplified version.

45 There is a dual aspect of this point as the degree to which a developing country's legal system is classed as 'ideal' is incorporated in the World Bank's Doing Business score, meaning that, even if investors are not particularly bothered by the shape of the legal system, they cannot avoid taking it into consideration if they choose to consult World Bank expertise and other 'ease of doing business' facts and figures. 
As already noted, both epistemological categories and normative frames can shift over time. These transformation points are one of the main foci of sociological enquiry. Rationalities, as the categories actors use to interpret and re-enact their social surroundings, can shift quickly or gradually and can assimilate or diverge. Changes can be organic (bottom-up) from within society or can be precipitated by changes to regimes (top-down). The role of feedback loops shows how one can shift to mirror (or challenge) the other through repeated interactions. However, having established the rationalities of particular investors, the extent to which regimes should reflect these in order to guarantee an ideal investment climate raises many more questions. 
